REVIEW ARTICLE

\title{
Social Return on Investment (SROI): An Innovative Approach to Sustainable Development Goals for Sexual and Reproductive Health Programming in sub-Saharan Africa
}

\author{
Shubha R. Kumar ${ }^{1}{ }^{*}$ and Aduragbemi Banke-Thomas ${ }^{2,3}$ \\ Institute for Global Health, Keck School of Medicine, University of Southern California, Los Angeles, California, USA ${ }^{1}$; Centre \\ for Reproductive Health Research and Innovation, Lagos State University College of Medicine, Ikeja, Lagos, Nigeria ${ }^{2}$; McCain \\ Institute for International Leadership, Arizona State University, Tempe, Arizona, USA ${ }^{3}$
}

*For Correspondence: Email: shubha.kumar@usc.edu; Phone: +1 (323) 442-7236

\begin{abstract}
Despite efforts, sub-Saharan Africa did not achieve many key Sexual and Reproductive Health (SRH) targets under the Millennium Development Goals. In the post 2015 era, the Sustainable Development Goals (SDGs) will frame decisions on donor priorities and resource allocations. Successfully addressing SRH challenges in sub-Saharan Africa have been blunted due to fragmentation of SRH interventions in planning and implementation, lack of coherence between policies and program implementation, resulting in poor program performance and lack of accountability. We suggest the Social Return on Investment (SROI) framework offers a strategic approach for sub-Saharan Africa in support of the implementation, monitoring and evaluation of SRH programs given its capacity to capture social and economic impacts, stakeholder participation, and sensitivity towards key human rights concerns relevant to SRH. SROI disrupts a "business as usual" approach for one that is systematic, participatory, and supportive of economic and human rights needs for success in the SDG era. (Afr J Reprod Health 2016 (Special Edition); 20[3]: 85-93).
\end{abstract}

Keywords: Sustainable Development Goals; Social Return on Investment; SROI; Sexual and Reproductive Health; sub-Saharan Africa; Human Rights

\section{Résumé}

Malgré les efforts, l'Afrique subsaharienne n'a pas atteint beaucoup d'objectifs clés de santé sexuelle et de la reproduction (SSR) dans le cadre des objectifs du millénaire pour le développement. Dans l'ère post-2015, les objectifs de développement durable (ODD) encadreront les décisions sur les priorités des donateurs et les allocations de ressources. Aborder avec succès les défis de SSR en Afrique sub-saharienne a été émoussée en raison de la fragmentation des interventions SSR dans la planification et la mise en œuvre, le manque de cohérence entre les politiques et la mise en œuvre du programme, ce qui entraîne une mauvaise 'exécution du programme et un manque de responsabilité. Nous suggérons que le retour social sur le cadre de l'investissement (RSSI) offre une approche stratégique pour l'Afrique subsaharienne à l'appui de la mise en œuvre, le suivi et l'évaluation des programmes de SSR compte tenu de sa capacité à capter les impacts sociaux et économiques, la participation des parties prenantes, et la sensibilité envers les préoccupations clés des droits de l'homme relatives à la SSR. Le RSSI perturbe une approche de «la vie continue comme si de rien n'est» pour celui qui est systématique, participatif et solidaire par rapport aux besoins économiques et des droits de l'homme pour réussir dans l'ère des ODD. (Afr J Reprod Health 2016 (Edition Spéciale); 20[3]: 85-93).

Motsclés: Objectifs de développement durable, retour social sur l'investissement; SROI, santé sexuelle et de la reproduction,' Afrique sub-saharienne, droits de l'homme.

\section{Introduction}

\section{Sexual and reproductive health shortcomings in sub-Saharan Africa in the pre-2015 era}

While there has been significant progress overall in the decline of the maternal mortality ratio since 1990, including a 44\% decline within the African region, this region also showed the least amount of progress globally and now accounts for more than 6 out of 10 maternal deaths globally ${ }^{1}$. Despite several efforts, sub-Saharan Africa specifically missed out on achieving many of the Sexual and Reproductive Health (SRH) targets in the Millennium Development Goals (MDG) era. In the sub-Saharan Africa of today, SRH faces major challenges including maternal mortality and morbidity, unsafe abortion, unwanted pregnancies, family planning, infertility, Sexually Transmitted Infections (STIs) including HIV/AIDS, cervical cancer and the other cancers of the reproductive tract, harmful practices and violence against 
women and children ${ }^{2}$. Key indices that reflect these challenges include that of the estimated 289,000 maternal deaths in 2013 globally, subSaharan Africa alone accounted for 62\% $(179,000)$ and HIV/AIDS contributed $10 \%{ }^{3}$. Of these deaths, about 31,000 are due to unsafe abortion in the subregion ${ }^{4}$. Still within the region, $25 \%$ of married women of reproductive age have an unmet need for family planning ${ }^{2,5}$, with evidence suggesting even higher unmet need ranging from $48 \%-64 \%$ in some sub-Saharan African countries ${ }^{6}$. Each year, about 50 million women are infected with one of four major curable STIs - chlamydia, gonorrhea, syphilis or trichomoniasis. These STIs are known to increase risk of subsequent pelvic inflammatory disease, infertility, pregnancy complications and severe health problems in newborns ${ }^{7}$. Finally, cervical cancer accounts for $22 \%$ of all female cancers in the region, with 34 out of every 100,000 women being diagnosed with cervical cancer and 23 out of every 100,000 women dying from cervical cancer annually 8 .

Sexual and reproductive health in the post2015 era and emphasis on subjective wellbeing

During the MDG era, many global progress records were set, framing a shift in the international discourse and debate on development. While progress towards the MDGs was impressive in many ways, including the reduction in maternal and child mortality, several limitations of the MDGs also became apparent over time. Such limitations included a limited focus, resulting in verticalization of health and disease programmes in countries, a lack of attention to strengthening health systems, the emphasis on a "one-size-fits-all" development planning approach, and a focus on aggregate targets rather than equity ${ }^{2}$. As the MDGs drew to an end, global leaders reviewed lessons learned and engaged in discussions on how best to frame development for the next 15 years. These discussions bore the Sustainable Development Goals (SDGs), including the setting of a new health goal ("Ensure healthy lives and promote well-being for all at all ages"). The SDGs are more ambitious in their size and broader in scope relative to the MDGs, consisting of 17 goals and 169 targets that are applicable to all countries, rich and poor equally, and take into account the economic, social and environmental challenges of our world ${ }^{9}$. Specifically, as it relates to the SRH field, the SDGs comprise several relevant goals and targets which embrace many key aspects of SRH including access to SRH services, integration of reproductive health into national strategies and programs, broad sexuality education, the ability of individuals to make decisions regarding their own health (Target 3.7), eliminating discrimination (Target 5.1) and violence (Target 5.2), eliminating harmful practices like female genital mutilation (5.3) and improving maternal health (Target 3.1) (See Table 1$)^{10,11}$.

These SDGs and targets will frame future decisions on how decision makers and donors allocate global and national resources, including financial and human resources. They will also frame policy priorities of donors between now and 2030.

In addition, in the post 2015 era, the global agenda, led by the United Nations makes a key shift to emphasize the "subjective wellbeing" of individuals ${ }^{12}$. Though this concept was described long ago ${ }^{13}$, the recognition of the importance of understanding the interpretation of the perception of individuals benefiting from an intervention has just been highlighted in this agenda. Subjective wellbeing has been defined as "people's cognitive and affective evaluations of their lives"14

This concept of subjective wellbeing will mean that public health practitioners as a whole will need to be able to understand and measure specific needs of specific populations ${ }^{12}$. This has implication for SRH programing, as it is well established that there is a broad range of sociocultural, economic and religious factors that influence sexual and reproductive health choices that individuals make ${ }^{15,16}$. As such, the need for us to be able to capture disaggregated data that would allow for identifying areas and/or populations of the most need, their type(s) of need and how best to implement interventions that address those needs. Previous use of district, national and regional averages fell short in highlighting areas of most need. 
Table 1: The 17 SDGs Including Specific Targets on Sexual and Reproductive Health.

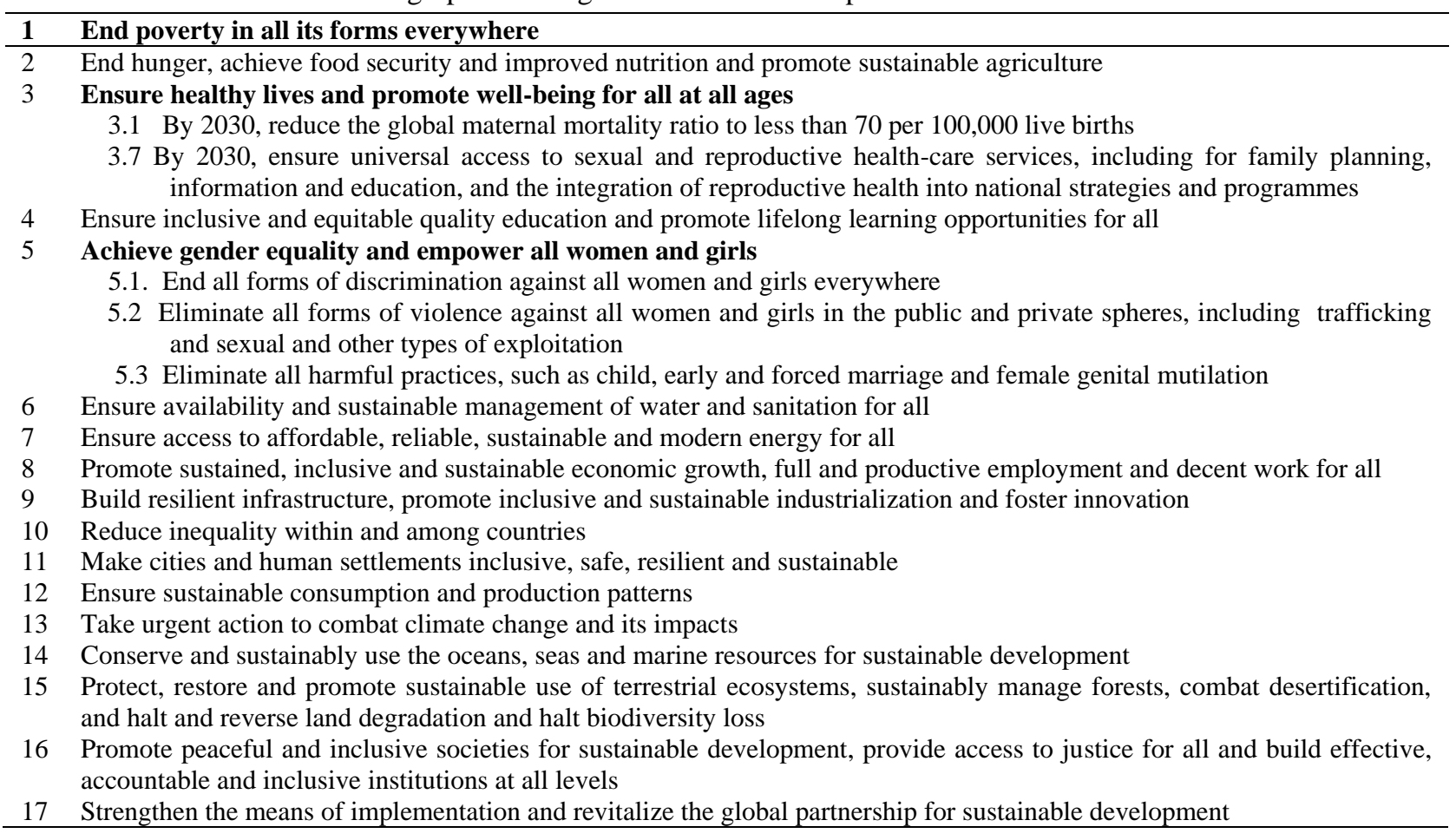

\section{Discussion}

Economic and human rights case for how implementation of SRH programs in subSaharan Africa need to be done differently

There is sufficient evidence to suggest that several of the SRH interventions that can improve SRH in sub-Saharan Africa are not only effective, but are also cost-effective ${ }^{17}$, and therefore these would be good value-for-money for donors and governments. For example, a previous estimate showed that if all unmet need for modern contraception were satisfied in sub-Saharan Africa, unintended pregnancies would drop by $83 \%$, from 18 million to three million per year; and unsafe abortions would decline by $84 \%$, from 5.7 million to 0.9 million $^{7}$. It appears that a key problem in sub-Saharan Africa is not the SRH interventions themselves, but how these interventions are being implemented.

According to the World Health Organization (WHO) in Africa ${ }^{18}$, efforts to tackle some of the SRH issues and challenges in sub-Saharan Africa have been significantly blunted due to fragmentation of SRH interventions in terms of planning and implementation, lack of coherence between policies and program implementation, resulting in poor program performance and lack of accountability. Clearly, these kinds of issues can limit successful traction of the SDGs and ultimately, limit the attainment of the SDGs in sub-Saharan Africa if not addressed.

There is a need to therefore explore frameworks that support engagement of all key stakeholders including women themselves and their partners, foster intersections between policy makers and beneficiaries and improve accountability mechanisms including SRH data systems. In the post-2015 era, it will be critical that only the most effective, cost-effective and culturally appropriate SRH interventions adapted for their local settings are implemented.

In addition, it is increasingly recognized that human rights are essential to achieve sustainable development, including in the realization of SRH. While the MDGs served as a proxy for certain economic and social rights, several critical human rights linkages were ignored ${ }^{19}$. The SDGs provide renewed opportunity to strengthen human rights but this will require human rights-based approaches to programming as well as monitoring 
and evaluation (M\&E) to truly achieve equitable growth and inclusive development ${ }^{20}$. Critics argue that while the SDGs provide valuable opportunities to advance human dignity and rights, the SDGs as articulated represent missed opportunities let alone a consistent rights-based approach to the goals and targets ${ }^{21,22}$. Upholding principles of transparency, accountability, participation and inclusion in the design and implementation of development activities will be required to support the realization and protection of human rights in the post-2015 era ${ }^{23}$.

In terms of SRH, nine key relevant human rights principles and standards have been identified as central to human-rights based approaches to SRH programs and their M\&E: nondiscrimination, availability, accessibility, acceptability, quality, informed decision-making, privacy and confidentiality, participation and accountability $^{24}$. In the context of human rights, participation refers to whether states ensure active, informed participation of individuals in decisionmaking that affects them, including on matters related to their health. Similarly, in the context of human rights, accountability refers in part to the state's requirement to fully comply with its obligations under all international and regional human rights treaties to which it is a party. Accountability provides individuals with assurance and evidence of how their government has fulfilled its relevant human rights obligations. It is also the mechanism by which the government explains and justifies the steps it has taken. Redress is incorporated into this process. Given the complexity of the health sector and its importance to the fulfilment of rights in the delivery of sexual and reproductive health information and services, multiple transparent and independent accountability mechanisms are needed ${ }^{24}$. While the need for human rights-based approaches to SRH programming has been explicitly recognized, a review of the literature cites a lack of evidence in this area ${ }^{25}$.

\section{Social return on investment (SROI) approach offers a way forward in the post- 2015 era}

An innovative approach to Planning, Monitoring and Evaluation (PM\&E) known as social Return on Investment (SROI) analysis may offer a useful framework in the context of the SDGs for promoting accountability, participation and transparency in program implementation and M\&E. An SROI analysis measures social, economic and environmental outcomes of an intervention and while it is not typically focused on monitoring human rights outcomes and therefore would not be classified as a rights-based approach to M\&E, we argue that it is an approach that supports key human rights concerns in addition to supporting value-for-money measurements. For example, in terms of human rights concerns, SROI explicitly involves the input and participation of key stakeholders, including intended beneficiaries, in determining changes that have/will take place from their perspectives, and in estimating the value of these changes. In addition, when calculating the SROI, no one key stakeholder is prioritized over the other in terms of valuation of the change - facilitating an equity approach rather than one driven by power dynamics. Furthermore, through participatory engagement and dissemination of findings with key stakeholders, SROI analysis facilitates accountability between implementers, donors, and intended beneficiaries rather than just upward accountability that typically results from the majority of M\&E approaches. In these ways, an SROI approach to programming can facilitate approaches to implementation and $\mathrm{M} \& \mathrm{E}$ that are more sensitive to human rights concerns compared to other non-participatory approaches commonly used. The following paragraphs elaborate on the SROI framework and how it may be a relevant strategy to approach SDG programming and M\&E in a way that is sensitive to both human rights and value-for-money concerns.

\section{Overview of SROI}

As defined in the most recent guideline ${ }^{26}$, social return on investment (SROI) is a framework for measuring and accounting for broader social, economic and environmental outcomes (referred to as the "triple bottom line" ${ }^{27}$ ) of an intervention, program, policy or organization from the perspective of multiple stakeholders. The SROI framework can be used retrospectively to measure and account for the value of outcomes that have 
Figure 1: Six Stages of SROI Approach

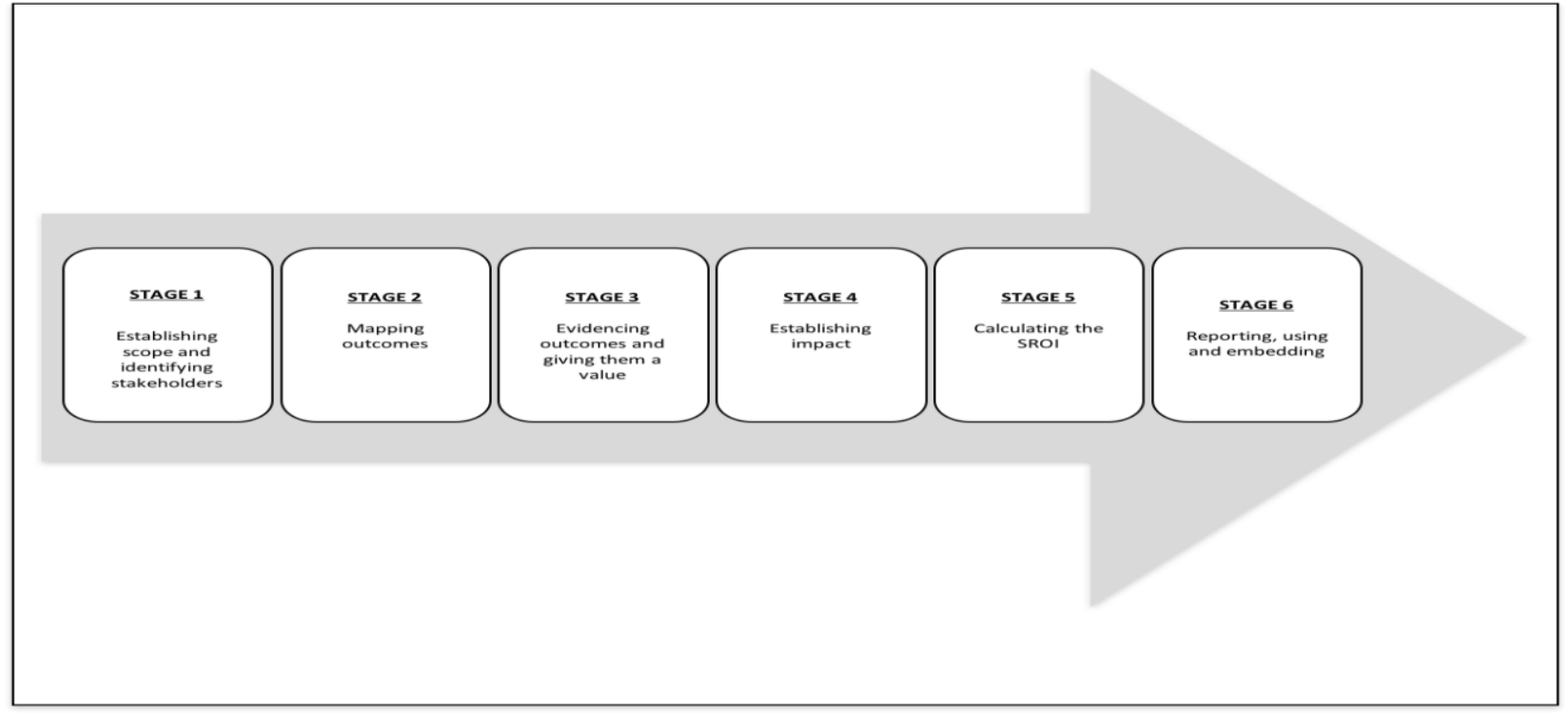

already happened (evaluative) or be used to prospectively predict how much value will be created if an intervention meets its intended outcomes (forecast). SROI allows an estimation of a broader benefits-to-costs ratio $^{26}$ and is used to report value-for-money of an intervention ${ }^{28}$. For example, a ratio of 3:1 indicates that an investment of \$1 delivers \$3 of social value.

The framework was initially developed by the Roberts Enterprise Development Fund (REDF) in $1996^{29}$ and it has since been updated. The most updated framework involves six stages: establishing scope and identifying stakeholders, mapping outcomes, evidencing outcomes and giving them a value, establishing impact, calculating SROI and reporting, using and embedding the findings ${ }^{26}$ (Figure 1).

The appeal for and application of SROI has continually grown across many sectors ${ }^{30}$, including in public health ${ }^{28}$. A 2015 systematic review on the application of the SROI framework in public health globally ${ }^{28}$ showed that it has been applied in SRH. Of the 39 studies retrieved from both peerreviewed and grey literature in the review, five were focused on SRH interventions, including one in Africa on an anti-stigma and discrimination program targeted at people living with $\mathrm{HIV}_{\mathrm{AIDS}}{ }^{31}$. In this example ${ }^{31}$ which was conducted in Mumbwa and Mazabuka in Zambia, the researchers used focus groups to determine the critical stakeholders of the study, defined what happened to the various stakeholder groups (including people living with HIV, their families, health care providers and non-governmental organisations) and what impact (positive and negative) the intervention had on the group. This was combined with quantitative data including financial values and proxies for monetising outcomes. Following data collection, the analysis involved calculating change attributable to the programme, what would have happened anyway, how long the change lasted and the net present value over a five-year period. All these data were then used to establish the SROI ratio of the intervention in the two sites (Mumbwa (1:21.20) and Mazabuka (1:13.75)). The analysis also highlighted an important finding that for people living with HIV/AIDS, efforts to reduce the stigma that they experience often increases their cost of living and can push them further into poverty.

As seen in the example described above, SROI provides a platform for meaningful engagement of key stakeholders and allows for outcomes of interventions to be described in ways unique to the stakeholders themselves ${ }^{32}$. This is critical for SRH and capturing subjective wellbeing, particularly in sub-Saharan Africa where multiple cultural nuances affect how SRH interventions are accepted by beneficiaries and implemented by programmers. Furthermore, SROI 
allows researchers and evaluators to capture "soft outcomes" that would otherwise not have been reported $^{33,34}$. Like in the example described above $^{31}$, where the authors were able to capture the value of a soft, yet critical outcome like stigma. In addition, the approach may be useful in elucidating unmet need when it comes to various SRH interventions, which may have otherwise gone unnoticed or unreported, since in SROI direct engagement is made with stakeholders and efforts are made to build a holistic picture of the intervention's impact (including both positive and negative).

In addition to the process and results of an SROI analysis, the seven key principles that underpin how SROI analysis should be applied are relevant to both economic and human rights concerns related to the SDGs ${ }^{26}$. (Table 2).

Table 2: Seven key Principles of SROI Approach.

\begin{tabular}{ll}
\hline 1 & Involve stakeholders \\
\hline 2 & Understand what changes \\
3 & Value the things that matter \\
4 & Only include what is material \\
5 & Do not over-claim \\
6 & Be transparent \\
7 & Verify the result \\
\hline
\end{tabular}

The first principle, 'involve stakeholders', suggests that stakeholders (i.e., those people or organizations that experience change as a result of the activity) will be best placed to describe the changes that occur as a result of an intervention and therefore need to be identified and then involved in consultation throughout the analysis, in order that the value, and the way that it is measured, is informed by those affected by the activity. This principle directly suggests the participation of intended beneficiaries, a key component of human rights-based approaches to programming.

The second principle, 'understand what changes', suggests the articulation of how change is created and that this be evaluated through evidence gathered, recognizing positive and negative changes as well as those that are intended and unintended. This principle requires the theory of how these changes are created to be stated and supported by evidence. This principle supports data-driven decision-making which is central to how economic and human rights decisions are (ideally) made.

The third principle, 'value the things that matter', suggests the use of financial proxies in order that the value of the outcomes can be recognized. Many outcomes are not traded in markets and as a result their value is not recognized. Financial proxies should be used in order to recognize the value of these outcomes and to give a voice to those excluded from markets but who are affected by activities. This will influence the existing balance of power between different stakeholders, facilitating equity in rights terms, while facilitating an assessment of value-formoney that is central to economic decisionmaking.

The fourth principle, 'only include what is material', suggests the determination of what information and evidence must be included in the accounts to give a true and fair picture, such that stakeholders can draw reasonable conclusions about impact. This principle requires an assessment of whether a person would make a different decision about the activity if a particular piece of information were excluded. It is a principle borrowed from the accounting world and important to facilitate sound decision-making without overwhelming amounts of information.

The fifth principle, 'do not over-claim', suggests organizations should only claim the value they are responsible for creating. This principle requires reference to trends and benchmarks to help assess the change caused by the activity, as opposed to other factors, and to take account of what would have happened anyway. It also requires consideration of the contribution of other people or organizations to the reported outcomes in order to match the contributions to the outcomes. This principle supports accountability between implementing agencies, donors, and beneficiaries.

The sixth principle, 'be transparent', suggests demonstration of the basis on which the analysis may be considered accurate and honest, and how it will be reported to and discussed with stakeholders. This principle requires that each decision relating to stakeholders, outcomes, indicators and benchmarks; the sources and methods of information collection; the different 
scenarios considered and the communication of the results to stakeholders, should be explained and documented. This will include an account of how those responsible for the activity will change the activity as a result of the analysis. This principle supports transparency in decisionmaking which is key to enable sound economic decisions and the fulfilment of human rights.

The seventh principle, 'verify the result', suggests appropriate independent assurance be performed. Although an SROI analysis provides the opportunity for a more complete understanding of the value being created by an activity, it inevitably involves subjectivity. Appropriate independent assurance is required to help stakeholders assess whether or not the decisions made by those responsible for the analysis were reasonable. It is also a principle borrowed from the accounting world and important to facilitating sound decisions that recognizes inherent subjectivity exists and suggests a way to deal with this rather than ignore it altogether.

\section{Conclusions}

The 'business as usual' format in which SRH programs have been implemented, monitored and evaluated remain unlikely to engender achievement of the SDGs in the post 2015 era. As global priorities increasingly emphasize embedding accountability, demonstrating valuefor-money, considering subjective well-being and identifying areas of most need as well as how best to meet these needs, there is an urgent need to consider robust and innovative approaches that can successfully advance SRH targets.

While the SROI framework has its limitations including difficulty in ascertaining financial valuation of "soft outcomes", establishing what would have happened without the intervention, particularly in complex environments and limited comparability of SROI ratios across interventions ${ }^{33,34}$, it still provides an approach to systematically account for broader outcomes of SRH interventions and the value-formoney of such interventions while actively supporting key human rights concerns. The framework offers potential to help SRH implementers and researchers to identify the most impactful, cost-effective and culturally sensitive SRH interventions, supporting the implementation and M\&E needs of the post 2015 era. Embedding such approaches will be critical in keeping stakeholders accountable, tracking progress, improving data systems to capture relevant, disaggregated data and in the end helping subSaharan Africa to achieve the SDGs. We suggest that SROI can provide value in the planning, implementation, M\&E of SRH interventions in the post-2015 era and invite it to be further explored by SRH programmers, researchers and policy makers.

\section{Declaration}

The authors declare that they have no competing interests.

\section{Contribution of Authors}

SK and $\mathrm{AB}$ conceived of the commentary and wrote and approved the manuscript.

\section{References}

1. WHO. Health in 2015: from MDGs, Millennium Development Goals to SDGs, Sustainable Development Goals.2015. Geneva: World Health Organization; 2015. 1-203 p. Available from: http://apps.who.int /iris/bitstream/ 10665 /200009/1/9789241565110_eng.pdf?ua=1.

2. WHO. Overview: Sexual and Reproductive Health. Programmes. 2015 [cited 2016 Feb 28]. Available from: http://www.afro.who.int/en /clusters-a-programmes/frh/sexual-andreproductivehealth/overview. $\mathrm{html}$

3. WHO, UNICEF, UNFPA, The World Bank, The United Nations Population Division. Trends in maternal mortality: 1990 to 2013. Geneva, Switzerland: World Health Organization; 2014.

4. WHO. Preventing unsafe abortion. Media Centre. 2015 [cited 2016 Mar 2]. Available from: http:// www.who.int/mediacentre/factsheets/fs388/en/.

5. UN. Meeting demand for family planning. New York; 2013. (Population Facts). Report No.: 2013/6. Available from:http://www.un.org/en/develop ment/desa/population/publications/pdf/popfacts/ popfacts_2013-6.pdf.

6. Chandra-Mouli V, McCarraher DR, Phillips SJ, Williamson NE, Hainsworth G, Patton G, et al. Contraception for adolescents in low and middle income countries: needs, barriers, and access. Reprod Health. 2014;11:1. 
7. Guttmacher Institute. Investing in Sexual and Reproductive Health in Sub-Saharan Africa. Fact Sheet. 2014 [cited 2016 Mar 2]. Available from: http://www.guttmacher.org/pubs/FB-Add ing ItUp2014-SSA.pdf.

8. WHO. Cervical cancer common amongst African women. Media Centre. 2015 [cited 2016 Mar 2]. Available from: http://www.afro.who.int/en/ media-centre/afro-feature/item/7557-cervicalcancer-common-amongst-african-women.html.

9. United Nations. Transforming our world: the 2030 Agenda for Sustainable Development. In: Resolution adopted by the General Assembly on 25 September 2015. New York: United Nations General Assembly; 2015. p. 1-7. Available from: http://www.ipu.org/ splz-e/unga16/2030-e .pdf.

10. UN. Sustainable Development Goals [Internet]. Sustainable Development Knowledge Platform. 2016 [cited 2016 Mar 3]. Available from: https: //sustainabledevelopment.un.org/sdgs.

11. Galati AJ. Onward to 2030: Sexual and Reproductive Health and Rights in the Context of the Sustainable Development Goals. Guttmacher Policy Rev. 2015;18(4). Available from: https://www.guttmacher.org/sites/default/files/ pdfs/pubs/gpr/18/4/gpr1807715.pdf.

12. UN. The road to dignity by 2030 : ending poverty, transforming all lives and protecting the planet: synthesis report of the Secretary-General on the post-2015 sustainable development agenda. In: 69th session of the General Assembly. New York: United Nations; 2014. Available from: http://www.un.org/ga/search/view_ doc.asp?symbol=A/69/700\&Lang=E.

13. Diener E. Subjective Well-Being. Psychol Bull. 1984;95(3):542-575.

14. Diener E. Subjective well-being. The science of happiness and a proposal for a national index. Am Psychol. 2000;55(1):34-43.

15. Arousell J, Carlbom A. Culture and religious beliefs in relation to reproductive health. Best Pract Res Clin Obstet Gynaecol. 2016;32:77-87.

16. Glinski A, Sexton M, Petroni S. Understanding the adolescent family planning evidence base. Washington D.C.; 2014. July 2014. Available from: http://www.icrw.org/files/ publications /FINAL Understanding the Adolescent Family Planning Evidence Base 7.30.pdf.

17. Singh S, Darroch JE, Ashford LS. Adding It Up: The Costs and Benefits of Investing in Sexual and Reproductive Health 2014. New York: Guttmacher Institute and United Nations Population Fund; 2014. Available from: https:// www.guttmacher.org/pubs/AddingItUp 2014.pdf.

18. WHO. Accelerating universal access to sexual and reproductive health: agenda for the African region of the World Health Organization.
Brazaville; 2013.

19. OHCHR. Human Rights and the 2030 Agenda for Sustainable Development. Issues. 2016 [cited 2016 Mar 13]. Available from: http:// www. ohchr.org/EN/Issues/MDG/Pages/The2030Agen da.aspx.

20. Jensen SLB, Corkery A, Donald K. Realizing rights through the sustainable development goals: the role of national human rights institutions. 2015. Available from: http://www.cesr.org/downloads /NHRI_realizing_rights_sdgs.pdf.

21. Williams C, Blaiklock A. Human rights discourse in the sustainable development agenda avoids obligations and entitlements: Comment on "Rights language in the sustainable development agenda: has right to health discourse and norms shaped health goals?" Int J Heal Policy Manag. 2016;5(6):387-390.

22. Harvard University Press. Human Rights and Sustainable Development. Blog. 2015 [cited 2016 Mar 14]. Available from: http:// harvardpress.typepad.com/hup_publicity/2015/ 10/human-rights-and-sustainable-developmentgoals.html.

23. ACSC. Where are human rights and good governance in the new Sustainable Development Goals? Johannesburg; 2015. Available from: http:// www.gppi.net/fileadmin/user_upload/media/pub /2015/KAS_CSO_2015_Human_Rights_ and_ Good_Governance.pdf.

24. WHO. Ensuring human rights in the provision of contraceptive information and services: Guidance and recommendations. Geneva: World Health Organization; 2014. Available from: http://apps.who.int/iris/bitstreamm/10665/10253 9/1/9789241506748_eng.pdf?ua=1.

25. Kumar S, Gruskin S, Khosla R, Narasimhan M. Human rights and the sexual and reproductive health of women living with HIV - a literature review. J Int AIDS Soc. 2015;18(6 Suppl 5):20290.

26. Nicholls J, Lawlor E, Neitzert E, Goodspeed T. A Guide to Social Return on Investment. 2nd ed. Cupitt S, Durie S, Inglis J, Leathem K, Lumley $\mathrm{T}$, Piper R, editors. Liverpool: The Cabinet Office; 2012. Available from:http://www. Neweconomics.org/publications/ entry/a-guideto-social-return-on-investment.

27. Norman W, MacDonald C. Getting to the bottom of triple bottom line. Bus Ethics Q. 2004;14(2):243-62.

28. Banke-Thomas AO, Madaj B, Ameh C, van den Broek N. Social Return on Investment (SROI) methodology to account for value for money of public health interventions: a systematic review. BMC Public Health. 2015;15:582.

29. Emerson J, Cabaj M. Social Return on Investment. Mak Waves. 2000;11(2). Available from: http://www.tamarackcommunity.ca/downloads/c 
life/mcabaj/mc_sroi.pdf.

30. Krlev G, Münscher R, Mülbert K. Social Return on Investment (SROI): State-of-the-Art and Perspectives. Heidelberg; 2013. Available from: https://www.csi.uniheidelberg.de/downloads/CS

31. I_SROI_Meta_Analysis_2013.pdf.

32. Brady R. The True Cost of Stigma: Evaluating the Social Return on Investment of the stigma and discrimination component of the Alliance's Africa Regional Programme II. Hove, United Kingdom; 2011. Available from: http://www .aidsalliance.org/assets/000/002/381/SROI_Zam bia_original.pdf?1453739463.
33. Lyon F, Arvidson M. Social impact measurement as an entrepreneurial process. Birmingham; 2011 [cited 2013 Oct 17]. (Briefing paper). Report No.:66. Available from: https://eprints.mdx.ac $. u k / 8835 /$.

34. Arvidson M, Lyon F, McKay S, Moro D. Valuing the social? The nature and controversies of measuring social return on investment (SROI). Volunt Sect Rev. 2013;4(1):3-18.

35. Millar R, Hall K. Social Return on Investment (SROI) and Performance Measurement. Public Manag Rev. 2013;15(6):923-41. 